\title{
Immediate Chest Wall Reconstruction After Oncoplastic Surgery
}

\author{
Jose M. Galbis-Caravajala, b, g, Miriam Estors-Guerrero ${ }^{\mathrm{a}, \mathrm{b}}$, Carlos A. Fuster-Diana ${ }^{\mathrm{b}, \mathrm{c}}$, Fernando Sanchez- \\ Garcia $^{\text {b, d }}$, Rafael Esturi Navarro ${ }^{\text {b, d }}$, Nestor Martinez-Hernandez ${ }^{\mathrm{a}, \mathrm{e}}$, Luis Yeste-Sanchez ${ }^{\mathrm{f}}$, \\ Arantxa Lafuente-Sanchis ${ }^{\text {a }}$
}

\begin{abstract}
Background: In this paper, we report our experience in the resection and immediate reconstruction of chest wall tumors, using oncoplastic surgery criteria.

Methods: This is a prospective study including 27 patients with malignant tumors of the chest wall (primary and metastatic) who underwent oncoplastic surgery with curative intent.

Results: In 15 cases, it was a sternal defect and in 12 , the ribs were involved. Immediate closure, in collaboration with teams of plastic surgeons, was conducted with different prostheses to provide wall stability and then be able to cover the defect with musculocutaneous flaps at different levels, depending on the need.

Conclusions: Extended resection of the chest wall is the best treatment for most tumors affecting this region. Reconstruction with mesh and musculocutaneous flap is an effective technique for repairing such defects, although not without morbidity.
\end{abstract}

Keywords: Chest wall reconstruction; Osteosynthesis material; Meshes; Chest wall oncoplastic surgery

\section{Introduction}

Chest wall resection may result from a variety of diseases: car-

Manuscript accepted for publication February 23, 2015

${ }^{a}$ Thoracic Surgery, La Ribera University Hospital, Alcira, Valencia, Spain ${ }^{b}$ School of Medicine, San Vicente Martir Catholic University, Valencia, Spain 'Unit of Breast, University General Hospital, Valencia, Spain

dPain Management, La Ribera University Hospital, Alcira, Valencia, Spain

eAnesthesia Intensive Care, La Ribera University Hospital, Alcira, Valencia, Spain

fPlastic, Reconstructive and Aesthetic Surgery, POVISA, Vigo, Pontevedra, Spain

'Corresponding Author: Jose Marcelo Galbis-Caravajal, Servicio de Cirugia Toracica, Hospital Universitario de La Ribera, Crt. Corbera Km1. 46600 Alcira, Valencia, Spain. Email: jgalbis@hospital-ribera.com

doi: http://dx.doi.org/10.14740/jcs262w cinomas (primary or metastatic), infections, radionecrosis, or traumatisms [1].

The resection may include bone frame (sternum and/ or ribs), soft tissue and skin. The type of reconstruction will depend on the affected location (especially anterior or lateral/ posterior defects) and the amount of the excision. Defects of one or two ribs, especially of posterior localization (subscapularis) can be closed directly; larger defects will require prosthesis $\left(\right.$ Marlex $^{\circledR}$ or Goretex ${ }^{\circledR}$ ) to cover the defect [2].

Large resections, or especially anterior defects, affecting the sternum require a reconstruction to restore necessary rigidity, so the chest might provide normal respiratory mechanics and offer protection of the organs it covers.

Various materials (Table 1) of osteosynthesis or prosthesis have been used to provide chest wall rigidity and to immediately cover the defects with muscle or musculocutaneous flaps. Multiple treatment combinations are possible, depending on the location and size of the defect, the state of the wall adjacent to it, and the preferences of the surgical team. Furthermore, we should deliver an acceptable esthetic result that will allow the patient to achieve an optimal quality of life [3].

In this paper, we report our experience in oncoplastic surgery (Table 2), which seeks to accomplish a cancer treatment procedure with acceptable esthetic results, after treating 27 chest wall tumors (primary or metastatic) with different reconstruction techniques.

\section{Material and Methods}

During a period of 12 years, we have performed oncoplastic surgery in 27 patients with chest wall tumors (Table 3 ): surgery included en bloc resection from skin to cavity, removal of the bone wall (costal-sternal), mesh placement and musculocutaneous flap.

Twelve (12) men were treated. Mean age was 51 years (32 - 80 years). In five cases, tumor embolization was performed prior to surgery. Regarding the histological type, the most frequent tumors were chondrosarcomas and chest wall involvement by breast carcinoma.

The lesions were palpable in all cases, with or without pain (32\% of cases). In 18 cases, lesions were biopsied prior to surgery: 12 by surgical incision and six by puncture.

The study of the lesion included a chest radiograph and 


\section{Table 1. Material for Chest Wall Reconstruction}

\begin{tabular}{l}
\hline Polyglycolic acid $\left(\right.$ LactoSorb $\left.^{\circledR}\right)$ : resorbable \\
Autologous bone/cadaver \\
Steel bars \\
Meshes \\
$\quad$ Mesh-methyl methacrylate (MMM) \\
$\quad$ Titanium \\
$\quad$ Goretex (polytetrafluoroethylene $\left(\right.$ PTFE $\left.^{\circledR}\right)$ ) \\
Cemented (Sandwich Technique) \\
Moldable titanium bars \\
Bars (Synthes ${ }^{\circledR}$ ) \\
Stratos ${ }^{\circledR}$ system: bar + rib clips \\
Intramedullary system (MatrixRIB $\left.{ }^{\circledR}\right)$ \\
\hline
\end{tabular}

computed tomographic (CT) scans of the affected area, extended to other places if there was suspicion of metastasis. The magnetic resonance imaging (MRI) was performed in 17 cases. In four cases, PET-CT was requested for metastatic extension study. No patient was subjected to chemotherapy or radiotherapy before surgery.

\section{Results}

Oncologic resection and chest wall reconstruction were performed in the same procedure. All cases were primary or metastatic malignancies. In the case of rib resection, the minimum number of ribs was 3 (range 3 - 6). In 15 cases, the main defect after surgery was sternal (Table 4), and in 12 was costal, anterior or lateral.

Closure of the chest wall was carried out with synthetic material: 10 cases of polytetrafluoroethylene (PTFE), six cases with titanium mesh, four with titanium rods, and seven with mesh-methyl methacrylate (MMM). The muscle flap was selected from three regions: pectoral (11), dorsal (11) and rectus abdominis (5).

The main complications are listed in Table 5. In one case, a change of prosthesis had to be performed given the possibility of extubation, and another patient required removal of the prosthesis for persistent cutaneous fistula after 2 months. Two patients died of respiratory distress in the days immediately following surgery.

\section{Discussion}

The anatomy and physiology of the chest wall and sternum are intimately intertwined. Various diseases can affect them, mainly radiation necrosis and infection, and tumors. The latter, either primary or metastatic, invades the chest wall, soft tissues and adjacent structures. Oncologic resection includes adequate preoperative assessment and chest wall reconstruction planning in the same procedure.
Table 2. Chest Wall Oncoplastic Surgery

Oncoplastic surgery: characteristics

Oncologic surgery with complete resection criteria

En bloc resection from skin to parietal pleura or affected organs

Resection of three or more ribs or sternum (total or partial)

Immediate reconstruction in the same surgical procedure

In the case of a chest wall lesion, silent or not, the first question that needs to be resolved is to determine the histological type. Radiological studies (chest radiography, CT and MRI) are useful for the preliminary assessment and evaluation of the degree of extension. Even though, definitive diagnosis requires a sample for pathological study. Cavanaugh [4] recommends an incisional biopsy for diagnosis and appropriate therapeutic management. The interpretation of the samples should be careful because potential diagnostic confusions can occur as with chondrosarcomas, which show alternating benign and malignant areas [5]. We took samples in 18 cases, 12 by incisional biopsy; in nine cases, surgery was decided directly because of the location (sternum) or progression of the disease, as in the case of recurrent breast carcinoma on the chest wall.

In five cases, on the day before surgery, arteriography and tumor embolization were performed due to the large size of the tumor and great tumor-associated vascularity.

In some cases, the administration of neoadjuvant therapy is useful in multidisciplinary treatment. In the present series, surgery was decided as the first option because the treated tumors would not have benefited from that type of therapy.

Once surgery has been decided, the strategy should be considered. The skin incision should include ulcerated areas (if any), and affected areas with a margin of $2 \mathrm{~cm}$ in the macroscopic view. The incision from skin to chest cavity allows us to explore it, considering the possibility of pleural and lung metastasis, and also organ involvement. The resection of structures at that level should be performed en bloc. Later, chest drains are placed in the area.

The next step is to provide stability to the chest wall: diverse material can be used for this purpose (Table 1). Costal defects can be stabilized with a mesh. However, the partial or total excision of the sternum requires a rigid prosthetic material [6] (titanium, steel, cemented mesh) to prevent respiratory failure and minimize the risk of respiratory complications [2, 7]. In our series we used mostly titanium bars/mesh in sternal defects with good results regarding wall stability, showing resistance to infection and compatibility with adjacent tissue.

The next step is soft tissue coverage. The muscles used are usually latissimus dorsi, pectoralis and rectus abdominis, as shown in Table 3 . In sternal defects, the pectoral muscle is preferred, and lateral defects, the latissimus dorsi. We use the rectus abdominis in extensive defects of the anterior wall, which require a large flap to cover the defect. Moreover, we used the omentum in two patients due to the associated infection. Omentoplasty is a difficult procedure [8] in some patients, mainly in cases of extensive resections, irradiated fields or recurrent tumors. We used it on two occasions, where both 
Table 3. Patients Included in This Study

\begin{tabular}{|c|c|c|c|c|c|}
\hline No. & Diagnosis & Defect & Age & Mesh & Flap \\
\hline 1 & Chondrosarcoma & $\mathrm{A}$ & 38 & PTFE & PT \\
\hline 2 & Chondrosarcoma & A & 54 & M-M & PT \\
\hline 3 & Desmoid tumor & $\mathrm{L}$ & 59 & M-M & DS \\
\hline 4 & Neurofibrosarcoma & A & 43 & PTFE & PT \\
\hline 5 & Breast carcinoma & A & 61 & PTFE & $\mathrm{RC}$ \\
\hline 6 & Chondrosarcoma & $\mathrm{L}$ & 29 & M-M & DS \\
\hline 7 & Rhabdomyosarcoma & $\mathrm{L}$ & 74 & PTFE & $\mathrm{RC}$ \\
\hline 8 & Lung carcinoma & A & 70 & PTFE & PT \\
\hline 9 & Schwannoma & $\mathrm{L}$ & 32 & PTFE & PT \\
\hline 10 & Breast carcinoma & A & 41 & PTFE & $\mathrm{RC}$ \\
\hline 11 & Thyroid carcinoma & A & 62 & M-M & DS \\
\hline 12 & Thyroid carcinoma & A & 63 & M-M & $\mathrm{RC}$ \\
\hline 13 & Chondrosarcoma & A & 50 & PTFE & $\mathrm{PT}$ \\
\hline 14 & Radio-induced sarcoma & $\mathrm{L}$ & 63 & M-M & $\mathrm{RC}$ \\
\hline 15 & Chondrosarcoma & $\mathrm{L}$ & 64 & M-M & DS \\
\hline 16 & Breast carcinoma & A & 43 & Titanium mesh & DS \\
\hline 17 & Breast carcinoma & A & 33 & Titanium mesh & DS \\
\hline 18 & Fibrous histiocytoma & A & 42 & Titanium mesh & DS \\
\hline 19 & Giant cell tumor & $\mathrm{A}$ & 55 & PTFE & PT \\
\hline 20 & Chondrosarcoma & A & 55 & Titanium bars & DS \\
\hline 21 & Breast carcinoma & A & 43 & Titanium mesh & PT \\
\hline 22 & Squamous cell carcinoma & TO & 80 & Titanium bars & PT \\
\hline 23 & Squamous cell carcinoma & $\mathrm{TO}$ & 77 & Titanium bars & PT \\
\hline 24 & Esophageal carcinoma & $\mathrm{L}$ & 42 & Titanium bars & DS \\
\hline 25 & Chondrosarcoma & A & 45 & Titanium mesh & $\mathrm{PT}$ \\
\hline 26 & Pleomorphic sarcoma & $\mathrm{L}$ & 76 & PTFE & DS \\
\hline 27 & Breast carcinoma & $\mathrm{A}$ & 44 & Titanium mesh & DS \\
\hline
\end{tabular}

A: anterior; L: lateral; TO: thoracic outlet; PTFE: polytetrafluoroethylene; MMM: mesh-methyl methacrylate; PT: pectoral; DS: dorsal; RC: rectus.

tumors had a large necrotic component.

Regarding complications, they range between $8 \%$ and $20 \%[9,10]$. Table 5 lists those that appeared in our series: the most frequent was partial flap necrosis, requiring partial debridements to heal the wound. Seroma appeared in cases where PTFE mesh was used, recovering well after drainage and local treatment. One patient required a change of prosthesis (PTFE by $\mathrm{MMM}$ ) due to paradoxical breathing, and not being able to

Table 4. Main Anatomical Defect Following Tumor Resection

\begin{tabular}{ll}
\hline Anatomical defect & Cases \\
\hline Anterior costal & 8 \\
Lateral costal & 4 \\
Superior sternal & 11 \\
Medium sternal & 4 \\
\hline
\end{tabular}

tolerate extubation until replacement. We had two postoperative deaths (on the first and fifth day): both were women with recurrent breast cancer to the sternum, and whose extension of the oncological disease must have been greater than what was supposed in the lungs, not allowing extubation and suffering early respiratory failure. Resection of recurrent breast cancer is indicated for wound hygiene with the major objective being

Table 5. Major Complications Associated With Surgery

\begin{tabular}{ll}
\hline Complication & Cases \\
\hline Chronic cutaneous fistula & 1 \\
Change of prosthesis & 1 \\
Persistent seroma ( $>15$ days $)$ & 2 \\
Partial flap necrosis & 4 \\
Perioperative death & 2 \\
\hline
\end{tabular}


a healed chest wall.

In short, chest wall immediate reconstruction after oncoplastic surgery requires proper planning to choose a suitable material for each patient and coordination between different surgical teams.

\section{Conflict of Interest}

None declared.

\section{References}

1. Rathinam S, Venkateswaran R, Rajesh PB, Collins FJ. Reconstruction of the chest wall and the diaphragm using the inverted Y Marlex methylmethacrylate sandwich flap. Eur J Cardiothorac Surg. 2004;26(1):197-201.

2. Chapelier A. Resection and reconstruction for primary sternal tumors. Thorac Surg Clin. 2010;20(4):529-534.

3. Noble J, Sirohi B, Ashley S, Ladas G, Smith I. Sternal/ para-sternal resection for parasternal local recurrence in breast cancer. Breast. 2010;19(5):350-354.

4. Cavanaugh DG, Cabellon S, Jr., Peake JB. A logical approach to chest wall neoplasms. Ann Thorac Surg. 1986;41(4):436-437.
5. Pairolero PC, Arnold PG. Chest wall tumors. Experience with 100 consecutive patients. J Thorac Cardiovasc Surg. 1985;90(3):367-372.

6. Weyant MJ, Bains MS, Venkatraman E, Downey RJ, Park BJ, Flores RM, Rizk N, et al. Results of chest wall resection and reconstruction with and without rigid prosthesis. Ann Thorac Surg. 2006;81(1):279-285.

7. Gonfiotti A, Santini PF, Campanacci D, Innocenti M, Ferrarello S, Janni A. Use of moldable titanium bars and rib clips for total sternal replacement: a new composite technique. J Thorac Cardiovasc Surg. 2009;138(5):12481250 .

8. Shrager JB, Wain JC, Wright CD, Donahue DM, Vlahakes GJ, Moncure AC, Grillo HC, et al. Omentum is highly effective in the management of complex cardiothoracic surgical problems. J Thorac Cardiovasc Surg. 2003;125(3):526-532.

9. Mansour KA, Thourani VH, Losken A, Reeves JG, Miller JI, Jr., Carlson GW, Jones GE. Chest wall resections and reconstruction: a 25-year experience. Ann Thorac Surg. 2002;73(6):1720-1725; discussion 1725-1726.

10. Aghajanzadeh M, Alavy A, Taskindost M, Pourrasouly Z, Aghajanzadeh G, Massahnia S. Results of chest wall resection and reconstruction in 162 patients with benign and malignant chest wall disease. J Thorac Dis. 2010;2(2):8185. 